\title{
Improving quality of life for older people in the community: findings from a local Partnerships for Older People Project innovation and evaluation
}

\author{
Brenda Roe ${ }^{1,2}$, Roger Beech $^{3}$, Michelle Harris ${ }^{4}$, Bernard Beech $^{5}$, Wanda Russell ${ }^{6}$, Deborah Gent ${ }^{7}$, \\ Kathryn Lord ${ }^{8}$ and Angela Dickinson ${ }^{9}$ \\ ${ }^{1}$ Professor of Health Research, Evidence-based Practice Research Centre, Edge Hill University, UK \\ ${ }^{2}$ Honorary Fellow, Personal Social Services Research Unit, University of Manchester, UK \\ ${ }^{3}$ Reader in Health Services Research, Primary Care Sciences, Keele University, UK \\ ${ }^{4}$ Development Manager, NHS Stoke on Trent, Wigan Council, UK \\ ${ }^{5}$ Senior Lecturer, School of Nursing and Midwifery, Keele University, UK \\ ${ }^{6}$ Formerly Research Fellow, Centre for Health Planning and Management, Keele University, UK \\ ${ }^{7}$ Project Manager, Wigan Council, UK \\ ${ }^{8}$ Research Worker, Formerly Centre for Research in Primary and Community Care, University of Hertfordshire, UK \\ now Old Age Psychiatry, Institute of Psychiatry, King's College, London, UK \\ ${ }^{9}$ Senior Research Fellow, Centre for Research in Primary and Community Care, University of Hertfordshire, UK
}

\begin{abstract}
Background: Partnerships for Older People Projects (POPP) was a national initiative in England aimed at improving health, well-being and quality of life ( $Q \circ L)$ for older people by developing local services. This development paper reports the key findings of a local evaluation in relation to quality of life, well-being and health-related $\mathrm{OoL}$ to provide practical understanding at the local level about what this means in relation to the schemes delivered. Objectives: To identify the impact of POPP schemes received by older people in Wigan on their QoL and well-being; and establish their feedback on services using local indicators. Methods: Convenience samples of older people receiving services from three selected 'community facing low level' schemes were recruited over a two-month period. They completed a semi-structured questionnaire at baseline (T1) and at follow-up 6 weeks later (T2). Information was collected on health status and health-related $\mathrm{OoL}$ using the EQ-5D, biographical information, overall QoL and well-being as part of the national evaluation and a local indicator, feedback on services. Results: Response rates were $70 \%$ (T1 45/64, mean age 72 years) and $43 \%$ at T2 (25/58, mean age 55 years). Following receipt of these schemes improvements were found for self care, anxiety and depression, health status and QoL although these differences were not statistically significant due to the small sample size and loss to follow-up. Feedback on local service use related to schemes 'being fit for purpose' and 'aspects of service delivery'. Conclusion: This local evaluation illustrates a pragmatic approach to service development and delivery of preventative services, with potential to benefit health and well-being of older people and support their continued living independently in the community. It provides detail and better understanding of what this means locally to people in context of national findings.
\end{abstract}

Correspondence to: Professor Brenda Roe, Evidence-based Practice Research Centre, Faculty of Health, Edge Hill University, Ormskirk, Lancs L39 4QP, UK. Email: bhroe@aol.co.uk or brenda.roe@edehill.c.uk

(C) Cambridge University Press 2011 
Key words: evaluation; health status; older people; quality of life; service development; well-being

Received 7 August 2010; accepted 28 January 2011; first published online 11 March 2011

\section{Introduction}

Partnerships for Older People Projects (POPP) was an innovation funded by the Department of Health in England aimed at developing services for older people to promote their health, wellbeing and independent living in the community. The purpose was to make sustainable shifts in resources and culture away from institutional or hospital-based high-intensity crisis care towards earlier, better-targeted preventive interventions by offering a range of local person-centred schemes and integrated services (DH, 2006). The POPP projects and initiatives underwent local evaluations to inform local service developments, their sustainability and commissioning as well as a national evaluation (Windle et al., 2007; 2008; $2009 \mathrm{a} ; 2009 \mathrm{~b})$. The purpose of this paper is to report the local Wigan POPP evaluation, findings for improvements in health status, quality of life (QoL) and well-being and feedback on service users' experience. It discusses developments and implications locally, and in context with the national evaluation (Windle et al., 2009a; 2009b).

\section{Background}

POPP comprised a $£ 60$ million programme led by the Department of Health (DH), England and involved 29 local authority-led partnerships including health and third sector organisations (voluntary, community and independent organisations). There were $29 \mathrm{DH}$ designated pilot sites from May 2006 to March 2009 (19 from May 2006 and 10 from May 2007). Local evaluations of the projects were undertaken and the $\mathrm{DH}$ commissioned a national evaluation of the whole programme. The national evaluation identified 146 core local projects or schemes comprising individual services with the aim of improving health and well-being and reducing social exclusion and isolation with the involvement of older people locally in the initiatives. Two thirds were 'community facing' directed at promoting healthy living or reducing social isolation or exclusion, while the remainder were 'hospital facing' developed to avoid hospital admission or facilitate early discharge from acute or institutional care. Older people volunteers made important contributions as part of POPP delivery and evaluation (Windle et al., 2009a; 2009b).

\section{Health-related QoL}

Measuring and improving QoL and healthrelated QoL (HRQoL) in older people are important research and policy agendas due in part to increases in ageing populations, their requirements for care and implications for resources (Walker, 2004; Bowling, 2005a: 1-43). QoL as a construct and measure is complex due to the many aspects included, resulting in a taxonomy of models (Bowling, 2005a: 9) and resultant instruments available (Bowling, 2005b). Improving health, QoL, well-being and services for older people is a feature of international and government policies (Stein and Moritz, 1999; Philp, 2004; 2006; Welsh Assembly Government, 2008; WHO, 2010). There is increased emphasis on targeting integrated health and social care services in the community to maintain older people living independently rather than moving into institutional care and avoiding unplanned hospital admissions (DH, 2008). Involving older people in the development of services and research is also a recent feature of policy (Ross et al., 2005; INVOLVE, 2009a; 2009b).

\section{Wigan POPP}

This paper reports on a local evaluation of POPP, HRQoL findings and feedback on service use experiences. It sets outcomes in context with specific POPP services delivered and provides additional evidence to support and inform service development for older people in the community. POPP schemes and the POPP forum were developed by Wigan Council in partnership with local organisations 12 months prior to the successful Wigan POPP (http://www.wigan popp.org) and formed part of the first wave of initiatives in May 2006 (Beech et al., 2008; 2010). Fifteen POPP 
schemes were developed in Wigan and were accessed either by provider or self-referral to a central call centre Starting Point (run by Age Concern Wigan; Box 1). Starting Point acts as a co-ordinating centre, broker and central point of contact for referral and information and schemes could also be contacted directly by users and professionals. The local evaluation also reported on the nature of POPP schemes, client access, resources and outcomes as well as impacts on partnership working between organisations and the involvement of older people and service users in the delivery and evaluation of POPP (Beech et al., 2008; 2010).

\section{Methods}

\section{Objectives}

To identify the impact of POPP schemes received by older people in Wigan on their health status, QoL and well-being.

\section{Box 1 Wigan POPP schemes}

Scheme - agency
Time limited support/contact - Pensioners Link
Counselling - Pensioners Link
Rapid intervention - Crossroads Carers Scheme
Holistic home assessment (community health
development workers) - PCT
Black and minority ethnic (BME) carers and
mental health project - PCT
Handyperson - Age Concern
Gardening - Groundwork
Care and repair - Arena Options Care and Repair
Stop and lock - Police Victims Support
Crime prevention awareness - Greater
Manchester Police
Stepping out/physical exercise - Wigan Leisure
\& Culture Trust
Sheltered housing improvements - W\&L
housing
Respite facility - W\&L housing
Computers - W\&P housing
Assistive technology/telecare - Adult Services
Department

To establish older people's feedback on Wigan POPP services and their experiences using local indicators.

\section{Design}

Evaluation research using mixed methods was adopted to generate information on the impact of the local POPP schemes on service users (Beech et al., 2010: 271). This drew on guidance related to the phases for the development and evaluation of complex interventions; developing the intervention, piloting and assessment of feasibility, formal evaluation and reporting of the results (Medical Research Council, 2008).

\section{Samples and data collection}

Iterative approaches were adopted with schemes selected by agreement between the POPP Project Manager and scheme leads as part of the Wigan POPP Forum. The schemes were 'community facing' aimed at providing 'low level' intensity care, help or community support to prevent or delay older people requiring access to higher intensity and more costly forms of care (Beech et al., 2010: 270). Three schemes (gardening, assistive technology and counselling) were selected as feasible for this aspect of the evaluation reported in this paper and were judged as having the most potential impact on health status, QoL and well-being. Data collection, including the local indicator questions were presented as part of the research partnership for discussion with the Wigan POPP Forum and older people volunteers at Age Concern Wigan. Following a further presentation and discussion at an action-learning event, there was agreement to use the national HRQoL questionnaire, excluding questions on benefits and income, and local indicators - feedback on service use.

Convenience samples of clients from three schemes were targeted and included, gardening (253 clients referred up to 31 March 2007, 43 declined uptake and 210 received the scheme), counselling (30 clients referred up to 31 March 2007) and assistive technology (commenced from April 2007). Measures of HRQoL and well-being were obtained via quantitative data as part of the national evaluation (NE) of POPP and qualitative data for local indicators provided feedback on these services. Self-completion questionnaires were

Primary Health Care Research \& Development 2011; 12: 200-213 
issued to new clients over a two-month period (during March-April 2007), as this was judged feasible by scheme leads at two time points, on initial receipt of the POPP scheme (T1) and again six weeks later (T2) once they had completed use of the scheme to capture change over time. Questionnaires and information on the POPP evaluation and instructions for completion were issued to clients along with reply paid envelopes for their return by either the scheme leads or co-workers.

\section{Data collected}

Data were collected on health status, HRQoL, overall QoL and well-being using the questionnaire developed by the national team (Windle et al., 2009b). Data included HRQoL (EQ-5D; Dolan et al., 1995), overall QoL and well-being using a single self-rating question (Bowling, 2005a) and biographical information. In addition, local indicators capturing qualitative data on clients' service use and feedback on Wigan POPP schemes comprised three open-ended questions with free text responses developed as part of the earlier Innovations Forum Initiative evaluation (Beech et al., 2008; Box 2). The same data were collected at $\mathrm{T} 1$ and again at $\mathrm{T} 2$.

\section{Data analysis}

Quantitative data were analysed to provide frequencies, simple relationships and before and after measures for health status, QoL, utility scores for health status and biographical information. Data were compared at $\mathrm{T} 1$ and $\mathrm{T} 2$ for all respondents and then for matched pairs (those who responded at T1 and again at T2) using simple inferential statistics; means, ranges, $t$-tests and $\chi^{2}$ s in SPSS.

\section{Box 2 Local indicators - feedback on service use questions}

What has been your experience of the POPP schemes?

Has the service/scheme helped you?

If so, how has it helped?

If not please say why

How could we improve what we do? Do you have any suggestions?
Qualitative data were read verbatim independently by two members of the team and content analysis performed to identify potential themes and subthemes for each of the responses (Miles and Huberman, 1994). Responses to the local indicator questions were compared across the schemes at times $\mathrm{T} 1$ and $\mathrm{T} 2$ to compare and contrast responses.

\section{Rigour and trustworthiness}

The EQ-5D is a standardised generic multidimensional non-specific disease health profile that can provide a single index value for HRQoL and health status and is used for economic evaluation (see EuroQol Group http://www.euroqol.org; Dolan et al., 1995; Kind et al., 1999; Bowling, 2005a: 75; Sculpher, 2006). There is an emerging evidence of its use, suitability and sensitivity along with test and $r$-test scores compared with other QoL measures (Bowling, 2005b: 77). The questionnaire used as part of the NE team was piloted initially with users from the Public Involvement in Research Group, Centre for Research in Primary and Community Care, University of Hertfordshire and also received wider comment, discussion and agreement with subsequent revision (Windle, 2006). The local indicator questions - feedback on service use, previously developed and used (Beech et al., 2008) are open ended, practical and easy to complete. The themes and sub-themes emerging from the qualitative data were identified independently by two members of the team, and any differences were discussed and agreement reached by consensus.

\section{Ethical approval}

Ethics approval for the local evaluation of Wigan POPP use of the QoL questionnaire was obtained from the Multi-Research Ethics Committee by the NE team (no. 06/Q41/60) and for the QoL and local indicators - satisfaction with services questionnaire from Wigan Local Research Ethics Committee (LREC RMG/06/076) and Wigan Council Governance Committee.

\section{Results}

\section{Response rates and demographics}

The response rates were $70 \%$ for $\mathrm{T} 1(45 / 64)$ and $43 \%$ for the T2 $(25 / 58)$ providing 70 questionnaires for analysis (Table 1), with only 21 from gardening 
Table 1 Response rates

\begin{tabular}{llc}
\hline $\begin{array}{l}\text { Partnerships for Older } \\
\text { People Project }\end{array}$ & $\begin{array}{l}\text { Time 1 } \\
\%(n)\end{array}$ & $\begin{array}{l}\text { Time 2 } \\
\%(n)\end{array}$ \\
\hline All three schemes & $70(45)$ & $43(25)$ \\
Gardening & $56(20)^{\mathrm{a}}$ & $30(12)$ \\
Counselling & $94(17)^{\mathrm{b}}$ & $67(12)$ \\
Assistive technology & $47(8)$ & $6(1)$
\end{tabular}

${ }^{\mathrm{a}} 9.5 \%$ of total sample in receipt of gardening scheme.

${ }^{b} 57 \%$ of total sample in receipt of counselling scheme.

and counselling being able to measure before and after for matched pairs at the individual level. A majority completed the questionnaires themselves (Table 1). The majority of respondents were women (T1 28, $62 \%$ versus $17,38 \%$; T2 18, $72 \%$ versus $6,24 \%$ ) and from one ethnic group (White). The mean ages were 72 years at T1 (range 50-95) and 55 years at T2 (range 50-86). A wide variation in mean age for males responding at $\mathrm{T} 1$ and $\mathrm{T} 2$ due to higher proportions of males 80 years and above responding to $\mathrm{T} 1$ accounted for this difference (mean age 76 years $\mathrm{T} 1$ and 42 years $\mathrm{T} 2$ ). Mean ages for women were similar at $\mathrm{T} 1$ and $\mathrm{T} 2$ (70 versus 68 years). The majority of respondents lived in domestic housing (T1, 93\%, 42) with nearly half living alone or with another adult (T1 47\%, 21 for each category). Nearly half of respondents were widowed, a third were married and the majority were retired (Table 2).

\section{Health status}

Data for initial and follow-up health status are reported in Table 3. A majority reported some problems in walking about (T1 69\%, 31), performing usual activities (T1 56\%, 25) with 42\% (T1 19) having some problems washing and dressing themselves. Proportionally more people reported problems or were unable to perform their usual activities at $\mathrm{T} 1$ than at $\mathrm{T} 2$. This difference was upheld for self-care when matched pairs were examined (T1 versus $\mathrm{T} 2$ no problems $68 \%, 13$ versus $74 \%, 14$ with self-care; some or unable to self-care $32 \%, 6$ versus $24 \%, 5$ ), indicating a positive relationship between participation in the POPP scheme and an improved ability to self-care.

Sixty-seven percent of people receiving services from POPP reported moderate or extreme anxiety or depression at T1 compared with only $60 \%$ of people at T2 (Table 3). Around 57\% (17/30)
Table 2 Demographics

\begin{tabular}{|c|c|c|}
\hline & $\begin{array}{l}\text { Time } 1 \\
\%(n)\end{array}$ & $\begin{array}{l}\text { Time } 2 \\
\%(n)\end{array}$ \\
\hline \multicolumn{3}{|l|}{ Age (years) } \\
\hline Mean & 72 & 55 \\
\hline $50-69$ & $38(17)$ & $52(13)$ \\
\hline $70-79$ & $38(17)$ & $32(8)$ \\
\hline$\geqslant 80$ & $24(11)$ & $8(2)$ \\
\hline Missing & $0(0)$ & $8(2)$ \\
\hline \multicolumn{3}{|l|}{ Female: age (years) } \\
\hline Mean & 70 & 68 \\
\hline $50-69$ & $39(11)$ & $39(11)$ \\
\hline $70-79$ & $46(13)$ & 46 (13) \\
\hline$\geqslant 80$ & $14(4)$ & $14(4)$ \\
\hline \multicolumn{3}{|l|}{ Male: age (years) } \\
\hline Mean & 76 & 42 \\
\hline $50-69$ & $35(6)$ & $50(3)$ \\
\hline $70-79$ & $24(4)$ & $17(1)$ \\
\hline$\geqslant 80$ & $41(7)$ & $17(1)$ \\
\hline Missing & $0(0)$ & $17(1)$ \\
\hline \multicolumn{3}{|l|}{ Marital status } \\
\hline Single & $4(2)$ & $0(0)$ \\
\hline Married & $36(16)$ & $40(10)$ \\
\hline Cohabiting & $2(1)$ & $0(0)$ \\
\hline Widowed & $47(21)$ & $44(11)$ \\
\hline Divorced/separated & $11(5)$ & $12(3)$ \\
\hline Missing & $0(0)$ & $4(1)$ \\
\hline \multicolumn{3}{|l|}{ Time widowed } \\
\hline$<6$ months & $2(1)$ & $0(0)$ \\
\hline 6 months to $<1$ year & $9(4)$ & $16(4)$ \\
\hline 1 year to $<3$ years & $2(1)$ & $0(0)$ \\
\hline 3 years to $<5$ years & $7(3)$ & $8(2)$ \\
\hline$\geqslant 5$ years & $27(12)$ & $20(5)$ \\
\hline \multicolumn{3}{|l|}{ Accommodation } \\
\hline Domestic housing & $93(42)$ & $92(23)$ \\
\hline Residential housing & $2(1)$ & $4(1)$ \\
\hline Missing & $4(2)$ & $4(1)$ \\
\hline \multicolumn{3}{|c|}{ Number of adults in household } \\
\hline 1 & $47(21)$ & $52(13)$ \\
\hline 2 & $47(21)$ & $36(9)$ \\
\hline 3 & $2(1)$ & $0(0)$ \\
\hline 4 & $4(2)$ & $4(1)$ \\
\hline Missing & $0(0)$ & $8(2)$ \\
\hline \multicolumn{3}{|c|}{ Number of children in household } \\
\hline 0 & $87(39)$ & $60(15)$ \\
\hline 1 & $2(1)$ & $0(0)$ \\
\hline 2 & $2(1)$ & $4(1)$ \\
\hline Missing & $9(4)$ & $36(9)$ \\
\hline
\end{tabular}

experiencing anxiety or depression at $\mathrm{T} 1$ were in receipt of the counselling scheme. The matched pair data also found a positive but non-significant relationship between receipt of a POPP scheme and reduced feelings of anxiety and depression with proportionally more at $\mathrm{T} 2$ reporting they were not anxious or depressed (T1 $24 \%$ versus 
T2 29\%) and fewer reporting moderate feelings (T1 57\% versus T2 52\%) or extreme feelings of anxiety or depression (T1 19\% versus T2 14\%).

Higher proportions of people aged 70 years and over compared to those aged 50-69 years reported problems with mobility $(51 \%, 23$ versus $20 \%, 9)$, self-care $(36 \%, 16$ versus $8 \%, 4)$, performing usual activities $(49 \%, 22$ versus $22 \%, 10)$, experiencing pain $(56 \%, 25$ versus $3 \%, 15)$ and anxiety or depression $(40 \%, 18$ versus $27 \%, 12)$.

Proportionally fewer respondents described their health today as being worse than in the previous 12 months at $\mathrm{T} 2$ than at $\mathrm{T} 1$ (Table 4). When only matched pairs data were examined, proportionally more people reported their health

Table 3 Health status

\begin{tabular}{|c|c|c|}
\hline & $\begin{array}{l}\text { Time } 1 \\
\%(n)\end{array}$ & $\begin{array}{l}\text { Time } 2 \\
\%(n)\end{array}$ \\
\hline \multicolumn{3}{|l|}{ Self-care } \\
\hline No problems & $51(23)$ & $60(15)$ \\
\hline $\begin{array}{l}\text { Some problems washing and } \\
\text { dressing }\end{array}$ & 42 (19) & $28(7)$ \\
\hline Unable to wash or dress myself & $2(1)$ & $4(1)$ \\
\hline Missing & $4(2)$ & $8(2)$ \\
\hline \multicolumn{3}{|l|}{ Usual activities } \\
\hline No problem & $29(13)$ & $36(9)$ \\
\hline Some problems & $56(25)$ & $44(11)$ \\
\hline Unable to perform & $16(7)$ & $12(3)$ \\
\hline Missing & $0(0)$ & $8(2)$ \\
\hline \multicolumn{3}{|l|}{ Mobility } \\
\hline No problem & $29(13)$ & $32(8)$ \\
\hline Some problems walking about & $69(31)$ & $64(16)$ \\
\hline Confined to bed & $2(1)$ & $0(0)$ \\
\hline Missing & $0(0)$ & $4(1)$ \\
\hline \multicolumn{3}{|l|}{ Pain } \\
\hline No pain or discomfort & $11(5)$ & $12(3)$ \\
\hline Moderate pain or discomfort & $73(33)$ & $64(16)$ \\
\hline Extreme pain or discomfort & $16(7)$ & $16(4)$ \\
\hline Missing & $0(0)$ & $8(2)$ \\
\hline \multicolumn{3}{|l|}{ Anxiety } \\
\hline Not anxious or depressed & $33(15)$ & $28(7)$ \\
\hline Moderately anxious or depressed & $56(25)$ & $44(11)$ \\
\hline Extremely anxious or depressed & $11(5)$ & $16(4)$ \\
\hline Missing & $0(0)$ & $12(3)$ \\
\hline \multicolumn{3}{|l|}{ Counselling scheme - anxiety } \\
\hline Not anxious or depressed & $0(0)$ & $8(1)$ \\
\hline Moderately anxious or depressed & $71(12)$ & $62(8)$ \\
\hline Extremely anxious or depressed & $29(5)$ & $15(2)$ \\
\hline Missing & $0(0)$ & $15(2)$ \\
\hline \multicolumn{3}{|l|}{ Gardening scheme - anxiety } \\
\hline Not anxious or depressed & $60(12)$ & $46(6)$ \\
\hline Moderately anxious or depressed & $40(8)$ & $23(3)$ \\
\hline Extremely anxious or depressed & $0(0)$ & $15(2)$ \\
\hline Missing & $0(0)$ & $15(2)$ \\
\hline
\end{tabular}

status as being better at $\mathrm{T} 2$ and fewer the same or worse (better T1 19\% versus T2 30\%; same T1 $48 \%$ versus $\mathrm{T} 2$ 45\%; worse $\mathrm{T} 133 \%$ versus $\mathrm{T} 2$ $25 \%$ ). Proportionally more people aged 70 years and above compared to those aged between 50 and 59 years described their health as being worse (T1 24\%, 11 versus $13 \%, 6$ ).

Self-reported health status for those people in receipt of the three POPP schemes using the 'thermometer' scale where a score of 0 is the worst possible health state and 100 the best imaginable is reported in Table 4 . When the mid point of 50 is used as a cut-off, proportionally more people rated their health today between 51 and 85 at T2 compared to T1 (T2 76\%, 16 versus $\mathrm{T} 163 \%, 26)$ with a proportional positive difference in health status of $13 \%$. This proportional difference in subjective self-reported 'own health' status remained when only matched pairs data were examined and nearly doubled to $24 \%$ (0-50 T1 $57 \%$ versus T2 29\%; $51-85$ T1 $33 \%$ versus T2 $57 \%$; missing data $n=4$ ), although these differences were not significant.

\section{QoL and well-being}

The scores for the EQ-5D related to mobility, self-care, usual activities, pain or discomfort and anxiety or depression, are collated to provide a total utility score for overall QoL ranging between $<0$ and 1 . Scores of 0.3 or below represent extreme problems and poor QoL with 1 being the best and 0 and minus scores the worst possible. Total QoL scores were available for 43 respondents for $\mathrm{T} 1$ and 22 for T2 (Table 5). Proportionally fewer

Table 4 Own health - self-rating

\begin{tabular}{lcc}
\hline & $\begin{array}{l}\text { Time 1 } \\
\%(n)\end{array}$ & $\begin{array}{l}\text { Time 2 } \\
\%(n)\end{array}$ \\
\hline $\begin{array}{l}\text { Health today } \\
\text { Better }\end{array}$ & $11(5)$ & $24(6)$ \\
Much the same & $51(23)$ & $40(10)$ \\
Worse & $38(17)$ & $28(7)$ \\
Missing & & $8(2)$ \\
Own health thermometer & & \\
0-50 & $37(15)$ & $24(5)$ \\
$51-100$ & $63(26)$ & $76(16)$ \\
Missing & $(4)$ & $(4)$ \\
\hline
\end{tabular}

${ }^{\text {a }}$ Compared with the previous 12 months.

${ }^{\mathrm{b}} \mathrm{O}=$ worst possible health state and 100 is the best imaginable. 
Table 5 QoL and well-being

\begin{tabular}{|c|c|c|c|c|c|c|}
\hline \multirow[t]{2}{*}{$\overline{E Q-5 D}$} & \multicolumn{3}{|l|}{ Time 1} & \multicolumn{3}{|l|}{ Time 2} \\
\hline & $n$ & $\%$ & Valid \% & $n$ & $\%$ & Valid \% \\
\hline \multicolumn{7}{|l|}{ Total utility scores } \\
\hline 0 and minus scores & 5 & 11 & 12 & 1 & 4 & 4.5 \\
\hline $0.001-0.10$ & 1 & 2 & 2 & 1 & 4 & 4.5 \\
\hline $0.101-0.30$ & 6 & 13 & 14 & 6 & 24 & 27 \\
\hline $0.301-0.50$ & 1 & 2 & 2 & & & \\
\hline $0.501-1.00$ & 30 & 67 & 70 & 14 & 56 & 64 \\
\hline Total & 43 & 96 & 100 & 22 & 88 & 100 \\
\hline Missing & 2 & 4 & & 3 & 12 & \\
\hline Total & 45 & 100 & & 25 & 100 & \\
\hline \multicolumn{7}{|l|}{ QoL } \\
\hline Very good & 3 & 7 & 7 & 2 & 8 & 9 \\
\hline Good & 11 & 24 & 25 & 8 & 32 & 36 \\
\hline Alright & 16 & 36 & 36 & 8 & 32 & 36 \\
\hline Bad & 10 & 22 & 23 & 3 & 12 & 14 \\
\hline Very bad & 2 & 4 & 5 & 1 & 4 & 5 \\
\hline So bad, it could not be worse & 2 & 4 & 5 & 0 & 0 & 0 \\
\hline Missing & 1 & 2 & 2 & 3 & 12 & 14 \\
\hline QoL versus age groups (years) & $50-69$ & $\geqslant 70$ & Total & $50-69$ & $\geqslant 70$ & Total \\
\hline Very good - alright $n(\%)$ & $12(27)$ & $18(41)$ & $30(68)$ & $10(46)$ & $8(36)$ & $18(82)$ \\
\hline Bad - could not be worse $n(\%)$ & $4(9)$ & $10(23)$ & $14(32)$ & $2(9)$ & $2(9)$ & $4(18)$ \\
\hline
\end{tabular}

QoL $=$ quality of life.

A total utility score for overall QoL ranging between $<0$ to 1.0 . Scores of 0.3 or below represent extreme problems and poor $\mathrm{QoL}$ with 1.0 being the best and 0 and minus scores the worst possible.

people scored 0 or less than 0 at follow-up than on initial receipt of POPP and this difference was also found with the matched pairs. The proportion of scores ranging from 0.1 to 1.0 increased at followup for the total sample (T2 91\% 20/22 versus T1 $86 \% 37 / 43$; Table 5) but remained unchanged for the matched pairs (T2 versus $\mathrm{T} 186 \%, 18$ with $57 \%, 12$ scoring between 0.501 and 1.00 ).

Overall self-reported QoL and well-being indicated a positive change in proportions at follow-up (Table 5) that was also found with the matched pairs data (QoL: alright, good or very good T1 $66 \%, 14$ versus T2 $75 \%, 16)$. A higher proportion of people aged 70 years and above rated their QoL as bad, very bad or so bad it could not be worse compared to those aged 50-59 years on initial assessment (T1 23\%, 10 versus T2 9\%, 4). However, none of these differences were significant.

\section{Local indicators - feedback on service use}

Two main themes were identified 'schemes being fit for purpose', which related to meeting the intended needs of clients, were positive and had a beneficial outcome. And, 'aspects of service delivery' that related to clients' views on staff, friendliness, communication and timeliness. Across all three schemes positive comments were reported (Box 3). On identifying how schemes have helped them, the majority of comments were positive and related to the counselling and gardening schemes, which reflects that more people received those schemes than assistive technology. Thematically, this related to what the scheme provided and how it benefited them in terms of activities of daily living, independence, QoL and well-being and peace of mind for them and their families. In addition, data in the theme related to 'aspects of service delivery' described how the scheme or services were delivered in relation to staff manner, communication, ease of access and referral, timely responsiveness and access to other schemes (Box 3). Individual deviant cases were not found although it was notable that clients had less experience of schemes at $\mathrm{T} 1$ versus $\mathrm{T} 2$ due to being in initial receipt of the schemes, and reflected in their comments 'Not sure yet, equipment not fitted' and 'We hope so'. 


\section{Box 3 Identified themes and quotes for feedback on POPP schemes and suggestions for improvement}

\section{Theme: schemes being fit for purpose}

Typical quotes for counselling comprise;

'I have only accessed the counselling it is a wonderful service and extremely helpful getting me back on track and feeling independent.'

'Made me look at things with a different point of view which has empowered me.'

'Have talked my problems out and by doing this realised the key problems and moved forward. I am no means through it yet but it has helped.'

It is helped me look at problems in a different way.'

'Given me new understanding of myself and other people but mostly myself.'

'Met really nice friends in the drop in centre.'

'Helped to talk about problems and feelings in general.'

Typical quotes for gardening include;

'Made me feel better about the garden.'

'Made gardening easier.'

'I had a gardening problem of overgrown trees which I requested help with. The team removed them for me and relieved my anxieties. I also intend to request a safety fire check in the near future.'

'Just knowing there is someone to help.'

'Done jobs in the home and outside that I cannot do myself.'

' $I$ am long-term disabled and there is not a lot I can do for myself, that is, gardening and household tasks, the service has helped me in this regard.'

'Financially lightening the load in old age, physically helpful, friendly and caring, increasing quality of life.'

'Reduced garden workload made it more manageable for family helpers.'

'Give me piece of mind that at last the garden is going to be sorted out. I have been going to get a gardener to do it but it is who? And who can be trusted. Your scheme has given me confidence to get on with the job. Thank you.'

Quote for assistive technology;

'Peace of mind knowing someone can help me.'

\section{Theme: aspects of service delivery}

Typical quotes for counselling include;

'A quick access to counselling. Very surprised at access to this service, used to waiting months for anything... (with NHS).'

'Excellent, helpful and good listeners.' 
Box 3 Continued

'Excellent, always very helpful when I have asked for information or advice.'

Typical quotes for gardening include;

'I was very impressed with the men who did the jobs in my garden, they were all very nice.'

'Very good, excellent, helpful, very friendly staff.'

'Up to now everyone I have dealt with has been very helpful.'

'Knowing that your schemes are trustworthy and safe especially when we have moved into a new area, town from a city.'

Quote for assistive technology;

'Very good, helpful and friendly.'

\section{Service delivery: suggestions for improvement and expansion of schemes}

'Increase the counselling available to more people with services nearer to home so as to avoid travelling.'

'Access to support groups to meet other people with depression or who have experienced bereavement with a view to days out or breaks away.'

'Include specific advice on financial issues and form filling.' (It was noted that the Wigan Citizen's Advice Bureau do undertake this although the availability of service is to be reduced)

'Increase the number of "gardening teams" available and where possible to have a continued service after the six weeks.'

'Have set appointment times as to when to expect visits.'

Counselling was targeted at older people who had experienced bereavement, depression, loneliness and isolation and their typical quotes provide examples of positive benefits from receiving the POPP scheme. Comments related to gardening highlighted that gardening had been made easier and manageable, relieved anxiety and it was reassuring knowing there were people who could help along with providing access by referral to other POPP schemes and services.

Suggestions were given as to how POPP schemes could be improved or developed and related to service delivery and expansion of schemes (Box 3). Of the 253 referrals to the gardening service, up until the end of March 2007, 43 people refused the scheme because of the financial implications. It is unknown whether this was because people felt they could not afford it or that they felt it was not value for money or at the right price. Of the three schemes, it was only the gardening scheme that had a co-payment element to it. It would appear that finance is an important issue for future analysis and consideration. There was a general expression that the POPP schemes continue and that schemes involving younger people make a difference to older people's lives.

\section{Discussion}

\section{Limitations and strengths of the evaluation of QoL and local indicators}

This local evaluation of POPP and QoL adopted a pragmatic approach and was restricted to three 'community facing low level' preventive schemes that related to 'well-being - practical or emotional/social isolation' (Windle et al., 2009b: 149; Beech et al., 2010: 270). Consequently, only 
small numbers were included in the total sample and matched pairs analyses. Loss to follow-up is not uncommon with repeated measures surveys. These schemes were judged as having the most potential impact on QoL and health status by the POPP forum and leads. The duration of recruitment for data collection was also deemed most feasible. Despite not achieving statistical significance and largely self-reported results, the findings do provide indicators of benefit to individuals and have contributed to the development of services for older people locally. The project also demonstrates the importance of having local stakeholder involvement in evaluation for the sustainability and future development projects. The findings also informed the local evaluation related to service provision, processes of care, outcomes and costs (Beech et al., 2008; 2010) as well as the national evaluation of POPP on HRQoL, QoL and well-being (Windle et al., 2009a; 2009b).

The national POPP examined the HRQoL and QoL data according to types of schemes (community facing or hospital facing) compared to a proxy control sample drawn from the British Household Panel Survey but urge caution, as it is not possible to attribute statistical significance with type of scheme due to wide groupings and variation. The local context reported here is able to provide useful indications of how individual schemes can contribute to older people's QoL and well-being, although the sample was small. The quantitative results did not achieve statistical significance but did demonstrate a positive direction and tendency. The qualitative findings have provided context of the benefits of the schemes to individuals and their families and relate to fitness of purpose and service delivery. Larger samples with long-term follow-up are warranted that control for age and gender differences.

\section{Samples of service users}

In Wigan between May 2007 and January 2008, 7577 referrals were made to POPP schemes, with 5429 (85.9\%) receiving services (Beech et al., 2008; 2010). Over a quarter of a million people (264000) received POPP services over the 3 years of the national evaluation (Windle et al., 2009a; 2009b). The mean age of service users in the national sample was 75 years (range 40-101 years) with twothirds being women (Windle et al., 2009a; 2009b).
In our sample reported here, the mean age was 72 years (range $50-95$ years) with a similar majority being women $(62 \%)$. In the national sample, almost two-thirds $(63 \%)$ were aged 75 years and over, with $30 \%$ aged 85 years and over. In our sample, $62 \%$ were aged 70 years and above, with fewer being aged 80 and over compared to the national POPP indicating slightly higher proportions of people in the national sample were aged 75 years and above. Our sample was similar to the national POPP sample in terms of gender and mean age. One-third of our sample were married, similar to the national POPP. More of our sample lived in their own home or domestic housing than in the national sample (93\%, 42 versus $81 \%)$, with $47 \%$ of our sample either living alone or with another adult or relative. The percentage living alone in our sample is lower than that reported for all those in Wigan POPP $(63 \%, 3404)$. Nearly two-thirds of the national sample lived in designated deprived areas, which could account for the difference in accommodation. Nearly half of our sample were widowed or living alone, which are both indicators of potential need (Victor et al., 2002; 2005; Arber and Ginn, 2005; Phillips et al., 2010: 150-151).

\section{Health status}

A majority reported some problem in walking, performing usual activities and reporting moderate or extreme pain and are comparable with the national POPP sample (Windle et al., 2009b: 142). Gender, living alone and lack of social relations are associated with disability and are risk factors (Lund et al., 2010). Maintaining social relations is important for independence and participation in activities (Guralnik and Ferucci, 2003). Being married or cohabiting is protective against disability for men and women (Mor et al., 1989; Waite and Hughes, 1999), men only (Nilsson et al., 2008; Lund et al., 2010) and women only (Avlund et al., 2002).

In our sample, two-thirds reported moderate or extreme anxiety or depression that was reduced at follow-up and was also the case for the matched pairs. This was higher than for the national POPP sample (40\%, Windle et al., 2009b: 142). Social relations are associated with health outcomes (Mendes de Leon et al., 2003; Avlund et al., 2004) and satisfaction with them suggested to 
influence mental well-being and depression (Clay et al., 2008). Although our sample was too small to achieve statistical significance, it is of note that more than half of those having anxiety or depression were in receipt of the counselling POPP scheme and a proportional reduction in these symptoms was reported. This would indicate a 'fitness of purpose' for the local POPP services received. In the national POPP, anxiety and depression were higher in the younger age range than older $(53 \%$ age 50-64 years versus $44 \%$ aged 85 years and above; Windle et al., 2009b: 143). This is contrary to studies that have found depression is more prevalent in older people, particularly those living alone (Wilson et al., 2007; 2008; Chew Graham et al., 2007).

When asked to rate their own health today, proportionally fewer people described it as being worse at follow-up. This positive change in proportions for health status was also found for the matched pairs data and indicated proportionally more reporting feeling better having received POPP and fewer reporting their health as worse. This is a positive finding and while not statistically significant, it indicates a potential improvement in health status for people in receipt of POPP. Similarly, in the national sample, people perceived their health better following POPP (with $10 \%$ moving from much the same to better) although overall there was no significant change (Windle et al., 2009b: 146-147).

Using the thermometer scale for self-reported 'own health' status, proportionally more people rated their health better at follow-up compared to the initial assessment signifying improvement in health status from their perspective. When only the matched pairs data were examined this positive direction in 'own health' status increased in proportions by $24 \%$. This is also a positive finding in the direction of self-reported health status for people in receipt of POPP. In comparison, the national sample 'own health' status was maintained and they argue that due to the nature of the population general health may remain stable but people could become frail over time (Windle et al., 2009b: 147). In relation to low-level POPP services (Wellbeing Practical, such as including fitting grab rails, gardening) there was a $6 \%$ improvement in health status, $16 \%$ greater than the 'proxy control' ( $P=0.07$, Friedman). They suggest such schemes may reduce anxiety but not impact on physical health. However, for projects classed as Wellbeing-emotional/social isolation (62 projects), they found a 3\% deterioration in overall health status compared to the 'proxy control'. Although, fewer people reported feeling anxious or depressed at follow-up (T1 63\% versus T2 58\%; Windle et al., 2009b: 156-157). They suggest this indicates that interventions need to be targeted and that more specific health measures, rather than the EQ-5D should be used to evaluate outcomes on emotional well-being. However, Windle et al. (2009b: 159) report that the EQ-5D was appropriate for measuring change in physical health as indicated by reported benefit for people undergoing exercise classes.

Also of note in our study, is that more people aged 70 years and above reported problems with their mobility, self-care, performing usual activities, experience of pain/discomfort, anxiety or depression than people aged between 50 and 59 years. More people over 70 years rated their health as worse compared to those aged between 50 and 69 years, and again represents the fact that health status can diminish with increasing age and indicates an increase in potential care needs (Knodel and Ofstedal, 2003; Arber and Ginn, 2005; Bowling and Dieppe, 2005). Windle et al. (2009b: 142) also found increased problems with age, although feelings of anxiety and depression were the exception.

\section{QoL, well-being and POPP service use}

Proportionally fewer people reported extreme problems and poor HRQoL at follow-up indicating a potential positive change for those in receipt of POPP. The proportion of scores ranging from 0.1 to 1.0 increased at follow-up although there was no difference for the matched pairs. Fewer people rated their overall QoL as being 'bad, very bad or so bad it could not be worse' for the total sample at follow-up compared to when they were in initial receipt of the POPP schemes. This self-reported improvement for QoL remained for the matched pairs with a $10 \%$ increase in proportions for categories 'alright to very good' than 'bad/worse' and is a potentially positive finding. More people aged 70 years and above recorded a poorer overall QoL score compared to people aged 50-69 years, and although the difference was not significant, it is in keeping with older 
populations having or rating impaired health or overall QoL, although reasons for this can be relative and multi-faceted (Bowling, 2005a).

Windle et al. (2009a; 2009b) reported improvement in HRQoL for people receiving POPP services ('hospital facing' tertiary services (25\%); 'community facing' low-level preventative projects $2 \%$ ) compared to a 'proxy control sample'. They urge caution due to the large variation in the types of POPP services compared, and the fact that service users were old and frail. As such, they were more likely to experience deteriorating well-being and reported that between a fifth and one quarter of the national sample had lower initial levels of overall QoL compared to the normal 'proxy control'. Factors such as poverty, illness or bereavement may be more critical and have an impact on HRQoL than POPP services. Their HRQoL scores were substantially lower for those receiving POPP compared to the 'normal population' (MVH National Survey Data; Kind et al., 1999). In the national POPP sample, there were fewer people who reported perfect health compared to age matched controls. This was $54 \%$ for POPP and $73 \%$ for the 'normal population' for people aged 75 years and above (Windle et al., 2009b: 142). They also suggest that a single question to self-rated QoL is in itself multifactorial (life is so good it could not be better or life is so bad it could not be worse) and open to individual interpretation, circumstances, preferences and beliefs. They argue low-level POPP services may not impact on such a wide measure in a short time frame. Windle et al. (2009a; 2009b) found deterioration in QoL varied according to areas of deprivation and age. They also found that the higher the age range, the less overall QoL was perceived to have changed. A greater percentage of people aged 85 years and above reported their QoL remained the same compared to other age ranges and a greater number reported that it had improved. However, this could not be explained statistically (Windle et al., 2009b: 183). In our small sample, the $10 \%$ proportional change in positive direction for QoL and well-being for the matched pairs remained. It would seem that the POPP schemes (in particular, gardening and counselling) could potentially improve overall QoL and well-being and that specific targeted interventions may be of benefit. This was also inferred from the feedback on services using local indicators that provided qualitative evidence of POPP schemes being 'fit for purpose' and 'aspects of service delivery' which were appreciated. They clearly demonstrate the value of obtaining client feedback and context at a local level and not just relying on standardised health and QoL measures for informing the development and sustainability of local services. Windle et al. (2009b: 261) also found that small services, low level preventive and community facing, providing practical help and emotional support to older people can significantly affect their health, QoL and well-being. They experienced improved outcomes and reported greater satisfaction as result of receiving POPP services. They also noted a reduction in hospital emergency bed days resulted in savings, which was also one of the intended outcomes of the national POPP initiative. They reported that gains in efficiency for health services use did not appear to adversely impact social care resources, and partnership working between local authorities, health agencies and the voluntary sectors improved local relationships (Windle et al., 2009a).

\section{Conclusion}

Prevention is a continuum aimed at meeting highand low-level needs. While acknowledging the small sample and therefore caution, this local evaluation of Wigan POPP indicates that lowlevel intensity community-based projects such as gardening and counselling that are targeted to needs have the potential to improve health, QoL and well-being for older people. POPP services were deemed appropriate, fit for purpose, met needs, maintained independence, provided peace of mind and reassurance to older people and their families. This was also borne out in the findings of the national evaluation that has evaluated the broader range of POPP initiatives available, although due to the large and varying nature of schemes and the study design it was not always possible to directly explain positive findings to 'cause and effect'. This local evaluation has been able to explain some of the positive benefits and their contexts, which indicates the potential benefits of the development of such community schemes and the importance of client feedback. The challenge is to make such schemes widely available locally so that older people can 
benefit and remain in their homes and communities, which is increasingly important for ageing populations.

\section{Acknowledgements}

Wigan Council funded the local evaluation of Wigan POPP, which formed part of the National Evaluation of POPP funded by the Department of Health. Brenda Roe and Roger Beech were investigators and grant holders on the local evaluation of Wigan POPP and the National Evaluation of POPP. We are indebted to the Wigan POPP Partners and Forum who facilitated this work and to the older people of Wigan who participated. Wanda Russell was also part of the lcal evaluation team. Colleagues from the National Evaluation of POPP Team (Karen Windle, Anne Bowling, Angela Dickinson, Martin Knapp, Kathryn Lord, Richard Wagland) also informed the conduct of this work as part of the national evaluation.

\section{References}

Arber, S. and Ginn, J. 2005: Gender dimensions and the age shift. In Johnson, M.L., editor, The Cambridge handbook of age and ageing. Cambridge: Cambridge University Press, 527-38.

Avlund, K., Due, P., Holstein, B.E., Sonn, U. and Laukkanen, P. 2002: Changes in household composition as determinant of changes in functional ability among ld men and women. Aging Clinical and Clinical Experimental Research 14, 65-74.

Avlund, K., Lund, R., Holstein, B.E. and Due, P. 2004: Social relations as determinant of onset $\mathrm{f}$ disability in aging. Archives of Gerontology and Geriatrics 38, 85-99.

Beech, R., Roe, B., Russell, W., Russell, M., Beech, B. and Gent, D.; Wigan POPP Forum and Wigan Age Concern Volunteers. 2008: Evaluating Wigan's partnerships for older people project. End of project report. Retrieved 12 May 2010 from http://www.dhcarenetworks.org.uk/ library/Resources/Prevention/CSIP_Product/FINAL_ EVALUATION_REPORT-3.pdf

Beech, R., Roe, B., Russell, M., Beech, B. and Gent, D. 2010: Researching organizations: evaluating a partnership for older people project. In Roberts, P. and Priest, H., editors, Healthcare research. A textbook for students and practitioners. Chichester: Wiley-Blackwell, 269-81.

Bowling, A. 2005a: Ageing well: quality of life in old age. Maidenhead: Open University Press.

Primary Health Care Research \& Development 2011; 12: 200-213
Bowling, A. 2005b: Measuring health: a review of quality of life measurement scales, third edition. Maidenhead: Open University Press.

Bowling, A. and Dieppe, P. 2005: What is successful ageing and who should define it? British Medical Journal 331, 1548-51.

Chew Graham, C.A., Lovell, K., Roberts, C., Baldwin, R., Morley, M., Burns, A., Richards, D. and Burroughs, M. 2007: A randomised controlled trial to test the feasibility of a collaborative care model for the management of depression in older people. British Journal of General Practice 57, 364-69.

Clay, O.J., Roth, D.L., Wadley, V.G. and Haley, W.E. 2008: Changes in social support and their impact on psychosocial outcome over a 5 year period for African American and White dementia caregivers. International Journal of Geriatric Psychiatry 23, 857-62.

DH. 2006: Our health, our care, our say: a new direction for community services. London: The Stationery Office.

DH. 2008: Making a strategic shift to prevention and early intervention: a guide. London: Department of Health.

Dolan, P., Gudex, C., Kind, P., and William, A. 1995: A social tariff for EuroQoL: results from a UK general population survey. Discussion paper 138. Centre for Health Economics, University of York, York.

Guralnik, J.M. and Ferucci, L. 2003: Assessing the building blocks of function: utilizing measures of functional limitation. American Journal of Preventive Medicine 25, 112-21.

INVOLVE. 2009a: Senior investigators and public involvement. Eastleigh: INVOLVE.

INVOLVE. 2009b: Exploring impact: public involvement in NHS, public health and social care. Eastleigh: INVOLVE.

Kind, P., Hardman, G., and Macran, S. 1999: Populations norms for EQ-5D. Discussion paper 172. Centre for Health Economics, University of York, York.

Knodel, J. and Ofstedal, M.B. 2003: Gender and ageing in the developing world: where are the men? Populations and Development Review 29, 677-704.

Lund, R., Nilson, C.J. and Avlund, K. 2010: Can higher risk of disability onset among older people who live alone be alleviated by strong social relations? A longitudinal study of non-disabled men and women. Age and Ageing 39, 319-26.

Medical Research Council. 2008: Developing and evaluating complex interventions: new guidance. London: Medical Research Council Retrieved 12 May 2010 from http:// www.mrc.ac.uk/Utilities/Documentrecaord/index.htm?d= MRC004871

Mendes de Leon, C.F., Glass, T.A. and Berkman, L.F. 2003: Social engagement and disability in a community population of older adults: the New Haven EPESE. American Journal of Epidemiology 157, 633-42.

Miles, M.B. and Huberman, M. 1994: Qualitative data analysis: an expanded source book. London: Sage.

Mor, V., Murphy, J., Masterson-Allen, S., Willey, C., Razmpour, A., Jackson, M.E., Greer, D. and Katz, S. 1989: Risk of functional decline among well elders. Journal of Clinical Epidemiology 42, 895-904. 
Nilsson, C.J., Lund, R. and Avlund, K. 2008: Cohabitation status and onset of disability among older Danes: is social participation a possible mediator? Journal of Aging and Health 20, 235-53.

Phillips, J., Ajrouch, K. and Hillcoat-Nalletamby, S. 2010: Key concepts in social gerontology. London: Sage.

Philp, I. 2004: Better health in old age. London: Department of Health.

Philp, I. 2006: A new ambition for old age. Next steps in implementing the national services framework for older people. London: Department of Health.

Ross, F., Donovan, S., Brearley, S., Victor, C., Cottee, M., Crowther, P. and Clark, E. 2005: Involving older people in research: methodological issues. Health and Social Care in the Community 13, 268-75.

Sculpher, M. 2006: The use of quality-adjusted life years in cost-effectiveness. Allergy 61, 527-30.

Stein, C. and Moritz, I. 1999: A life course perspective of maintaining independence in older age. Geneva: WHO.

Victor, C.R., Scambler, S.J., Shah, S., Cook, D.G., Harris, T., Rink, E. and Wilde, S. 2002: Has loneliness amongst older people increased? An investigation into variations between cohorts. Ageing and Society 22, 585-97.

Victor, C., Scambler, S.J., Bowling, A. and Bond, J. 2005: The prevalence of, and risk factors for loneliness in later life: a survey of older people in Britain. Ageing and Society 25, 357-75.

Walker, A. 2004: Understanding quality of life I old age. Ageing and Society 24, 657-814.

Waite, L.J. and Hughes, M.E. 1999: At risk of on the cusp of old age: living arrangements and functional status among black, white and Hispanic adults. The Journals of Gerontology Series B Psychological Sciences and Social Sciences 54, S136-44.

Welsh Assembly Government. 2008: The strategy for older people in Wales 2008-2013. Living longer, living better. Cardiff: Welsh Assembly Government.
WHO. 2010: Aging and the life course. Retrieved 20 April 2010 from http://www.who.int/ageing/

Wilson, K., Mottram, P. and Sixsmith, A. 2007: Depressive symptoms in the very old living alone: prevalence, incidence and risk factors. International Journal of Geriatric Psychiatry 22, 361-66.

Wilson, K.C.M., Mottram, P.G. and Vassilas, C.A. 2008: Psychotherapeutic treatments for older depressed people. Cochrane database of systematic reviews. Issue 1. Wiley, Chichester.

Windle, K. 2006: National evaluation of partnerships for older people projects; Fanl discussion document: quality of life indicators. July 2008. CRIPACC, University of Hertfordshire, Hatfield.

Windle, K., Wagland, R., Lord, K., Dickinson, A., Knapp, M., Forder, J., Henderson, C., Wistow, G., Beech, R., Roe, B., and Bowling, A. 2007: National evaluation of partnerships for older people projects: interim report of progress. October 2007. Report to Department of Health, London.

Windle, K., Wagland, R., Lord, K., Dickinson, A., Knapp, M., Forder, J., Henderson, C., Wistow, G., Beech, R., Roe, B., and Bowling, A. 2008: National evaluation of partnerships for older people projects: interim report of progress. October 2008. Report to Department of Health, London.

Windle, K., Wagland, R., Forder, J., D’Amico, F., Janssen, D., and Wistow, G. 2009a: The national evaluation of partnerships for older people projects. Research summary 53 October 2009. Kent: Personal Social Services Research Unit.

Windle, K., Wagland, R., Forder, J., D’Amico, F., Janssen, D., and Wistow, G. 2009b: The national evaluation of partnerships for older people projects. Full report. October 2009. Kent: Personal Social Services Research Unit. 